\title{
Photocatalytic Degradation of Methylene Blue with ZnO Nanoparticles; a Joint Experimental and Theoretical Study
}

\author{
Mehdi Irani*, Tahereh Mohammadi and Sajjad Mohebbi \\ Department of Chemistry, University of Kurdistan, P.O. Box 66175-416, Sanandaj, Iran \\ * Correspondence to Mehdi Irani, E-mails: m.irani@uok.ac.ir, Irani.ir@gmail.com \\ Telefax: +98 - 8733624133
}

Received June 14, 2016; Accepted October 31, 2016.

\begin{abstract}
The present work focuses on the photocatalytic degradation and adsorption properties of Methylene Blue (MB) on $\mathrm{ZnO}$ nanoparticles from experimental and theoretical points of view. The photoreaction is carried out in a Pyrex photoreactor, equipped with a Krypton lamp. The kinetics of the degradation is explained in terms of Langmuir-Hinshelwood kinetic model. The results show that the pseudo-first-order equation is the model that gives the best fit to the experimental data. The value of the adsorption equilibrium constant is calculated as $0.128 \mathrm{~L} \mathrm{mg}^{-1}$. The quantum mechanical cluster approach is used to model the adsorption of $\mathrm{MB}$ on the $\mathrm{ZnO}$ (0001) facet. Geometrical optimizations and vibrational analysis are performed using density functional theory methods. The calculations show a negative charge transfer from the substrate to the photocatalyst. The calculated value of the adsorption energy is in the range of chemical adsorption energies.

Keywords: Methylene Blue; ZnO; Photoreaction; Langmuir-Hinshelwood; DFT.
\end{abstract}

\section{Introduction}

Photocatalytic degradation has been proved as a promising method for treatment of wastewater, contaminated with organic and inorganic pollutants. The process, as a means of removal of persistent water contaminants such as dyes and pesticides has attracted the attention of many researchers in recent years [1-3]. Many of these investigations have utilized aqueous suspension of semiconductors illuminated by UV light to photodegrade the pollutants. Zinc oxide $(\mathrm{ZnO})$ is one of the materials that has been used in large-scale as effective, inexpensive and nontoxic semiconductor photocatalyst for degradation of a wide range of organic chemicals [4-6].

The performance of a semiconductor photocatalyst (i.e. $\mathrm{ZnO}$ ) is strongly associated with the electronic structure of it [7-9]. It has been established that the photocatalytic degradation of an organic molecule/ion in solution is initiated by photogenerated holes $\left(\mathrm{h}^{+}\right)$in the valence band (VB) and electrons $\left(\mathrm{e}^{-}\right)$in the conduction band $(\mathrm{CB})$ of the semiconductor photocatalyst. The generated $\mathrm{h}^{+}$has a high oxidative potential, which permits a direct oxidation of the organic molecule/ion to reactive intermediates. In addition, hydroxyl radicals are reactive species, which can help in degradation of the organic substrate.
Resumen: El presente trabajo consiste en una aproximación teórica y experimental al estudio de la adsorción y degradación foto catalítica del azul de metileno sobre nanopartículas de $\mathrm{ZnO}$. La foto reacción se lleva a cabo en un foto reactor de Pírex equipado con una lámpara de Kriptón. La cinética de la degradación es interpretada en términos del modelo cinético de Langmuir-Hinshelwood. Los resultados experimentales se ajustan mejor a un modelo de seudo primer orden. El valor de la constante de equilibrio se calcula en $0.128 \mathrm{~L} \mathrm{mg}^{-1}$. Se utiliza el método mecano cuántico de clúster para modelar la adsorción de azul de metileno sobre la faceta (0001) del ZnO. Los cálculos muestran una transferencia de carga negativa del substrato hacia el foto catalizador. El valor de la energía de adsorción calculada está en el rango de energías esperado para la adsorción química.

Palabras clave: Azul de metileno; $\mathrm{ZnO}$; foto reacción; Langmuir-Hinshelwood; DFT.

The hydroxyl radicals can be generated either from the reaction of $\mathrm{h}^{+}$with water and ${ }^{-} \mathrm{OH}$ anions or from the reaction of dissolved $\mathrm{O}_{2}$ and $\mathrm{e}^{-}[6,10,11]$. The generation of $\mathrm{h}^{+}$and $\mathrm{e}^{-}$on a photocatalyst and possible reactions of $\mathrm{h}^{+}$and $\mathrm{e}^{-}$in an aqueous solution are schematically shown in Scheme 1.

The adsorption of reactant molecules/ions on photocatalysts is required as the critical step in heterogeneous photocatalytic oxidation processes. On the other hand, the treatment of the Langmuir-Hinshelwood (L-H) kinetic model is also subjected to the assumptions that the rate-determining step (RDS) of photocatalytic reactions involves reactants present in a monolayer at the photocatalyst-solution interface [12]. This kinetic model has extensively been used to describe the photooxidation kinetics of organic species [6, 13-16]. In this work, we also investigate $\mathrm{L}-\mathrm{H}$ kinetics and the corresponding parameters.

The adsorption of an organic molecule/ion on a photocatalyst can be modeled using quantum cluster method and then can be successfully investigated, using density functional theory (DFT) computations. DFT computations have been already performed for adsorption of organic molecules on photocatalyst surfaces [17-25] and various properties such as adsorption energies and geometries were estimated. However, DFT methods have not been employed to study either the adsorption of 


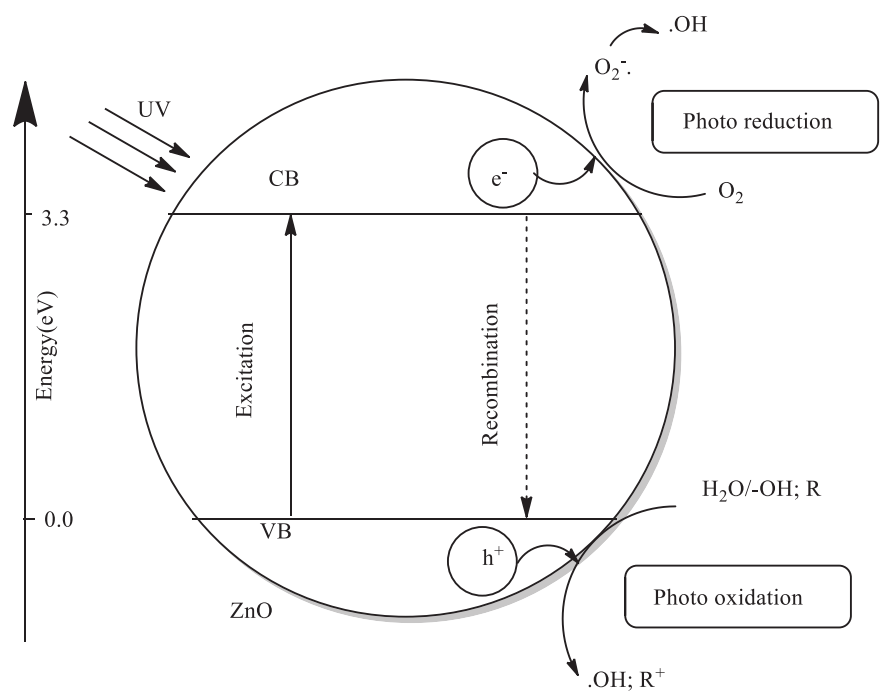

Scheme 1 .The generation of $\mathrm{h}^{+}$and $\mathrm{e}^{-}$on a photocatalyst and possible reactions of $\mathrm{h}^{+}$and $\mathrm{e}^{-}$in an aqueous solution.

Methylene Blue (MB) on $\mathrm{ZnO}$ nanoparticles or a relation between a substrate adsorption and the degradation rate.

$\mathrm{ZnO}$ nanoparticles have different facet exposures, including (1010) nonpolar, (1011) semipolar and (0001) polar facets. Liu et al. [26] synthesized three kinds of $\mathrm{ZnO}$ nanoparticles with these facet exposures. Their results showed that the predominant facet of $\mathrm{ZnO}$ sphere nanoparticles was polar (0001) facet. Since, the synthesized nanoparticles in this work have spherical shapes (Fig. 1), we model $\mathrm{ZnO}$ (0001) facet for the DFT calculations.

In this work, we study the photocatalytic degradation of $\mathrm{MB}$ on $\mathrm{ZnO}$ nanoparticles, experimentally and theoretically. The main objective of the experimental part is to investigate the photodegradation kinetics and obtaining kinetics parameters. In the theoretical part, we study the adsorption of $\mathrm{MB}$ on the $\mathrm{ZnO}$ nanoparticles and we look for a relation between the adsorption of MB and the photodegradation kinetics.

\section{Experimental and computational details}

\subsection{Materials and measurements}

MB (purity $98 \%, \lambda_{\max }=640 \mathrm{~nm}$ ), $\mathrm{ZnO}_{6} \mathrm{C}_{4} \mathrm{H}_{10}, \mathrm{C}_{2} \mathrm{H}_{2} \mathrm{O}_{4}$ and all other reagents were obtained from Merck Co. (Germany). Distilled water was used for preparation of various solutions. SEM images were obtained, using Field Emission Scanning Electron Microscopy, MIRA3 model. The photoreaction carried out with a 400W, Krypton lamp and the substrate concentration was monitored using UV/Vis Spectrophotometer, SPEKOL 1300.

\subsection{Preparation of $\mathrm{ZnO}$ nanoparticles}

To the $50 \mathrm{ml}$ solution of zinc acetate $(0.1 \mathrm{M}), 50 \mathrm{ml}$ oxalic acid solution $(0.1 \mathrm{M})$ was added and the resulting slurry was stirred for $12 \mathrm{~h}$, then the precipitate was collected and washed with acetone and distilled water. The wet powder was dried at about $120^{\circ} \mathrm{C}$ for $6 \mathrm{~h}$ to form the precursor and finally, calcined in $400{ }^{\circ} \mathrm{C}$ for $6 \mathrm{~h}$ to produce the nano-sized $\mathrm{ZnO}$ photocatalyst. The size of the product was confirmed by SEM images. Fig. 1. shows the SEM image of the $\mathrm{ZnO}$ nanoparticles with the size distribution in the range of $20-50 \mathrm{~nm}$.

\subsection{Photocatalytic degradation method}

For the photodegradation analysis, solutions containing known concentrations of MB and the photocatalyst $\left(300 \mathrm{mgL}^{-1}\right)$ were prepared and allowed to equilibrate for $45 \mathrm{~min}$ in darkness. Then $60 \mathrm{~mL}$ of the prepared suspension was transferred to a $500 \mathrm{~mL}$ Pyrex reactor. Irradiation was carried out with the Krypton lamp, which was put above the batch photoreactor. The distance between the solution and the UV source was constant, $20 \mathrm{~cm}$. All experiments were done in the natural $\mathrm{pH}$ of the solutions (about 5-6). The temperature was set to $298 \mathrm{~K}$, using a circulating water system. After that, the lamp was switched on to initiate the photoreaction. The reaction mixture was mixed by stirring and the suspension was sampled after appropriate illumination times. The concentration of the substrate in each degraded sample was determined with the spectrophotometer at $\lambda_{\max }=640 \mathrm{~nm}$. The photocatalytic setup of the reaction is shown in Scheme 2.

The reusability performance of the synthesized photocatalyst was evaluated. In fact, the catalyst was recycled for several times and reused. After each run, the photocatalyst was separated from the reaction media and washed with water several times. After reusing of $\mathrm{ZnO}$ for more than 10 times, no significant changes were observed. The photocatalytic performance of $\mathrm{ZnO}$ was decreased just $2.5 \%$ in present of $30 \mathrm{mg} \mathrm{L}^{-1}$ of $\mathrm{MB}$, $t=60 \mathrm{~min}$ and $300 \mathrm{mg}$ the photocatalyst under UV irradiation.

\subsection{Models and computational methods}

There are two approaches for modeling of solid surfaces. The first approach utilizes periodic boundary conditions to construct two-dimensional periodic slabs out of fragments of lattice. It is a computationally robust approach, which is appropriate to

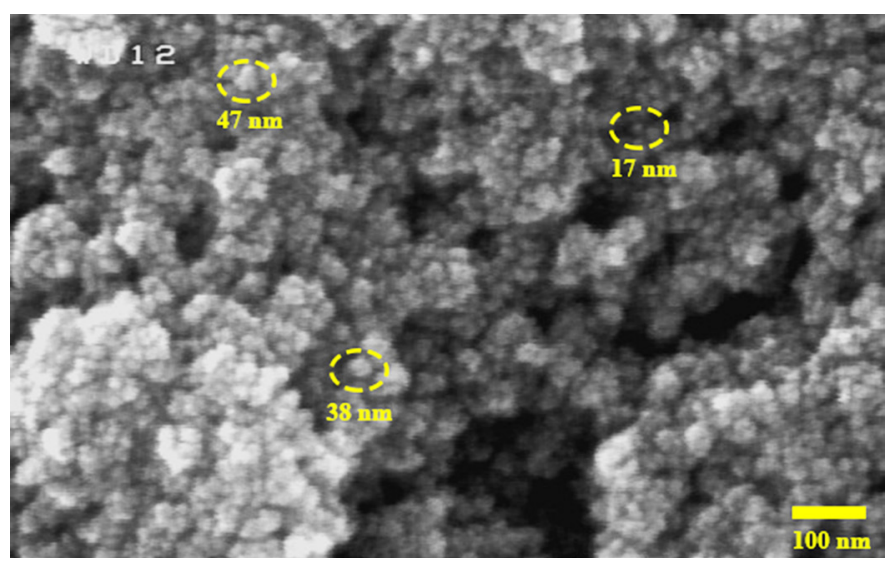

Fig. 1. SEM image of the synthesized $\mathrm{ZnO}$ nanoparticles. 


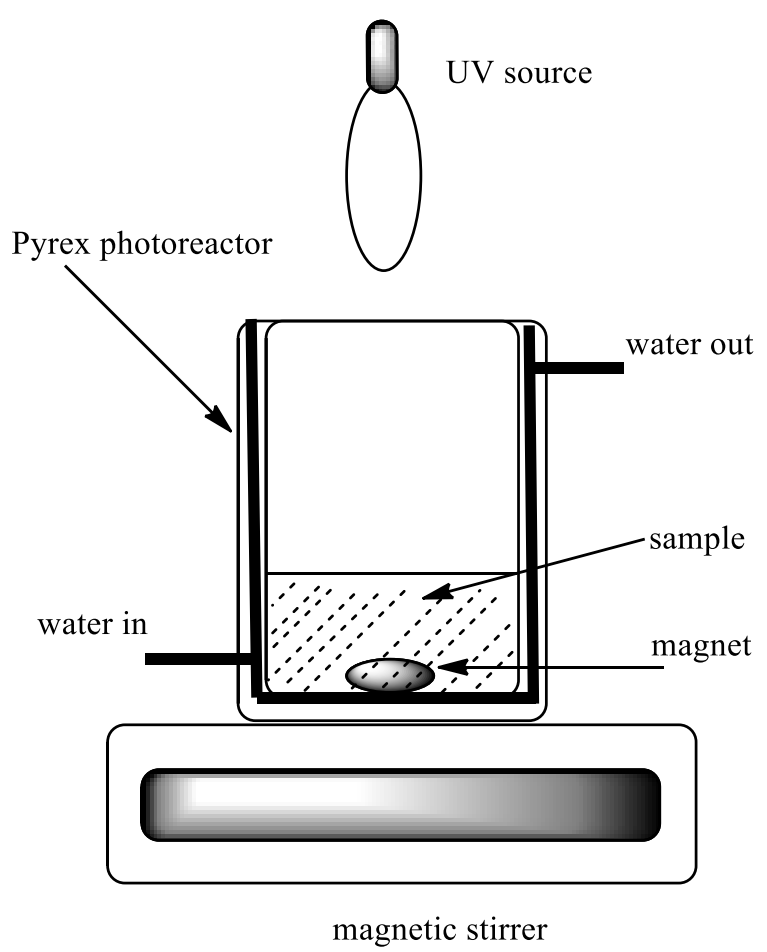

Scheme 2. Experimental setup of the photocatalytic process.

study bulk materials. The second approach makes use of fragments of a lattice of finite size that are called clusters. The latter approach is most suitable for modeling photoexcitation and was successfully applied in several studies for estimation of band gap, elucidation of adsorption energy and geometry of adsorbed molecules [17-25]. In the cluster approach, a number of atoms are cut out from the lattice of the crystal as a model of whole crystal. It reduces the number of atoms of the crystal to 10100 , which makes it possible to treat with DFT methods. To avoid that the model may change significantly from the starting crystal structure during the geometry optimization, the crystal atoms are keep fixed at their X-ray positions.

According to Onal et al. [25] the adsorption of small molecules is a relatively local phenomenon and a small metal oxide cluster can sufficiently present large cluster surfaces. Furthermore, Yang et al. [23] studied the adsorption of dimethyl methylphosphonate on $\mathrm{TiO}_{2}$ clusters. According to their results, the adsorption energy changes little when $\mathrm{TiO}_{2}$ cluster has more than three $\mathrm{Ti}$ atoms. Hence, we modeled the $\mathrm{ZnO}$ (0001) facet as $\mathrm{Zn}_{12} \mathrm{O}_{18}$ cluster which is much larger than the $\mathrm{Ti}_{4} \mathrm{O}_{16} \mathrm{H}_{16}$ and $\mathrm{V}_{2} \mathrm{O}_{9} \mathrm{H}_{8}$ clusters used by Vorontsov et al. [18] and Gao et al. [24]. The dangling bonds of the terminal oxygen atoms were saturated with 12 hydrogen atoms to result in $\mathrm{Zn}_{12} \mathrm{O}_{18} \mathrm{H}_{12}$, as the surface model. The size of the constructed model is big enough $(9.4 \AA \times 13.6 \AA)$ to cover whole of the MB molecule. The hydrogen atoms were then optimized (see Fig. 2. for the final structure of the cluster). The prepared cluster was then planted with an MB molecule. The geometry of the adsorbed moiety was optimized while the cluster was frozen.

All calculations reported in the present study were carried out using density functional theory with the B3LYP functional $[27,28]$, as implemented in the Gaussian03 program package [29]. For geometry optimizations, the 6-31G basis set was used for the C, N, O, S and H elements and the LANL2DZ [30] pseudopotential for $\mathrm{Zn}$ atoms. Natural bond orbital (NBO) analysis $[31,32]$ was used to calculate atomic charges on the optimized structures. The NBO calculations were performed at the same level of theory as the single-point energy calculations. The stationary points were confirmed as minima (no imaginary frequencies) by analytical frequency calculations at the same

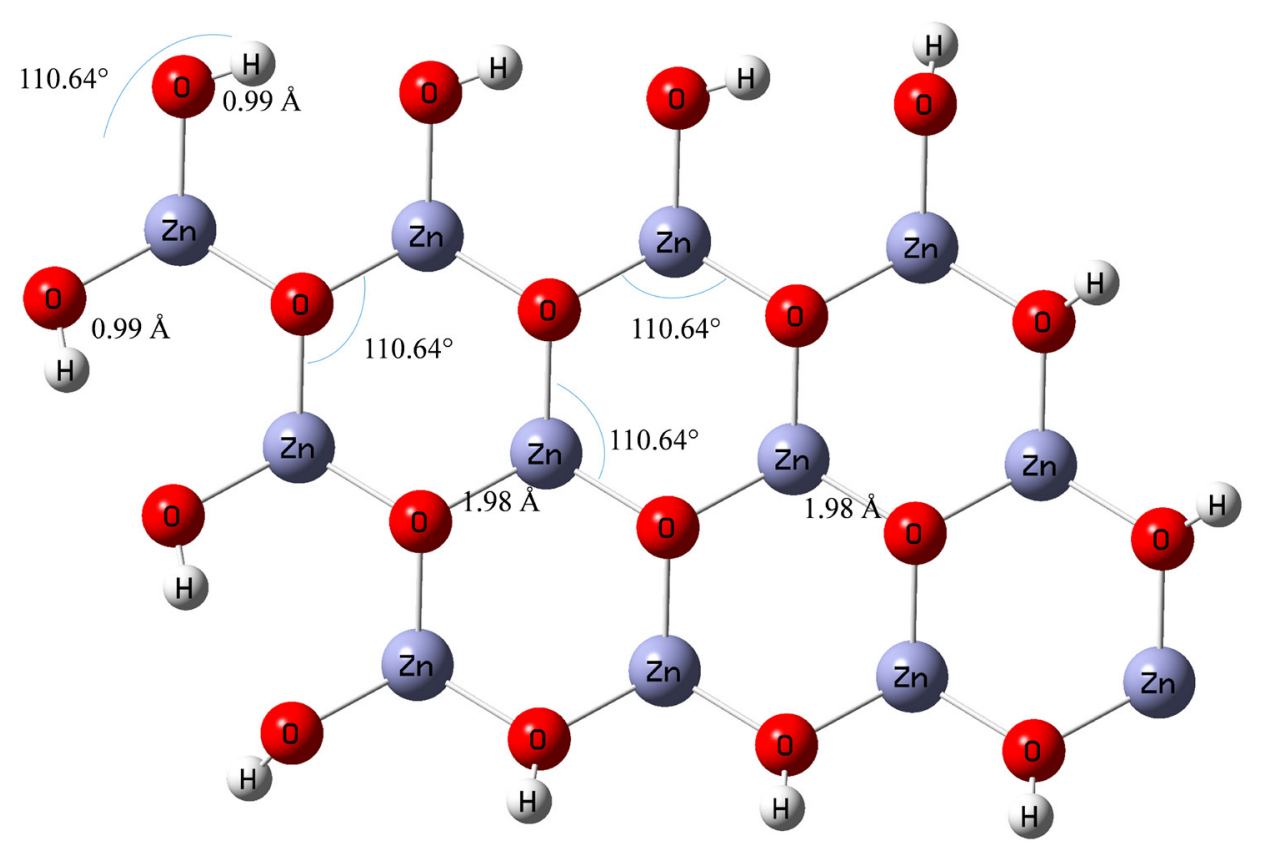

Fig. 2. The optimized structure of the $\mathrm{Zn}_{12} \mathrm{O}_{18} \mathrm{H}_{12}$ cluster, representing the $\mathrm{ZnO}(0001)$ facet. 
theory level as the geometry optimizations. The adsorption energy, $E_{\text {ads }}$ was then calculated using Eq. (1).

$$
E_{\text {ads }}=E(\mathrm{MB}+\text { cluster })-E(\mathrm{MB})-E(\text { cluster })
$$

where $E(\mathrm{MB}+$ Cluster) is the electronic energy of the cluster and the adsorbed $\mathrm{MB}, E(\mathrm{MB})$ is the electronic energy of the optimized $\mathrm{MB}$ in vacuum, and $E$ (cluster) is the electronic energy of the corresponding cluster.

\section{Results and discussion}

\subsection{Kinetics of the photocatalytic degradation}

Recent studies on photocatalytic reactions have been performed using the pseudo-first-order kinetics with respect to the substrate concentration $[6,14,16]$. However, to ensure the reaction order we tested both pseudo-first- and pseudo-second-order kinetics. The integrated forms of the pseudo-first- and pseudo-second-order models are according to Eq. (2) and Eq. (3), respectively.

$$
\begin{aligned}
& \ln \left([C]_{0} /[C]\right)=k_{\mathrm{obs} 1} t \\
& 1 /[C]=1 /[C]_{0}+k_{\mathrm{obs} 2} t
\end{aligned}
$$

where $[C]_{0},[C], k_{\mathrm{obs} 1}$ and $k_{\mathrm{obs} 2}$ represent the initial concentrations of $\mathrm{MB}$, the concentration of MB at time $t$, observed pseudo-first- and pseudo-second-order rate coefficients, respectively. The plots of $\ln \left([C]_{0} /[C]\right)$ and $1 /[C]$ versus $t$ at different initial MB concentrations are plotted in Fig. 3. and Fig. 4, respectively. The rate constants and the corresponding correlation coefficients $\left(R_{1}{ }^{2}\right.$ and $\left.R_{2}{ }^{2}\right)$ were calculated from the plots and are listed in Table 1. From the results obtained, the pseudo-first-order equation was the model that gave the best fit to the experimental data (its correlation coefficients are higher than 0.957, while those for pseudo-second-order are $0.892<R_{2}{ }^{2}<0.969$ ). Indeed, the correlation coefficient has been proposed as a good criterion for selection of a kinetic model [32].

The relationship between the initial degradation rate $\left(r_{0}\right)$ and $[\mathrm{C}]_{0}$ for heterogeneous photocatalytic degradation process has been described by the L-H model, which can be written as follows:

$$
\begin{aligned}
& r_{0}=k_{\mathrm{c}}\left(\left(K[C]_{0} /\left(1+K[C]_{0}\right)\right)=k_{\mathrm{obs} 1}[C]_{0}\right. \\
& 1 / k_{\mathrm{obs} 1}=1 / k_{\mathrm{c}} K+[C]_{0} / k_{\mathrm{c}}
\end{aligned}
$$

where $K$ and $k_{\mathrm{c}}$ are the L-H adsorption equilibrium constant and the kinetic rate constant of the surface reaction, respectively. Then we plotted $1 / k_{\text {obs } 1}$ versus $[C]_{0}$ ( Fig. 5 ). The plot of $1 / k_{\text {obs } 1}$ versus $[C]_{0}$ is linear with correlation coefficient close to 1 , $R^{2}=0.9917$. This confirms that the photodegradation of $\mathrm{MB}$ on $\mathrm{ZnO}$ obeys the $\mathrm{L}-\mathrm{H}$ kinetic model.

The adsorption equilibrium constant and the kinetic rate constant of the surface reaction can be obtained from the slope and intercept of the plot of $1 / k_{\text {obs } 1}$ versus $[C]_{0}$ (Fig. 5). However, Liu et al. proposed that the Langmuir adsorption coefficient is not independent of the incident light intensity for either a semiconductor film or a dispersed powder [3]. Ollis et al. indicated that $k_{\text {obs } 1}$ is linearly dependent to the light intensity [33]. According to Eq. (5), if $k_{\mathrm{obs} 1}$ is multiplied by a given number $I$ ( $I$ could be a factor from the light intensity), then the intercept of the plot of $1 / k_{\text {obs } 1}$ versus $[C]_{0}\left(1 / k_{\mathrm{c}} K\right)$ will be multiplied by $I$, and the slope $\left(1 / k_{\mathrm{c}}\right)$ will be divided by $I$. In addition, Ray et al. showed that adsorption constant of Phenol on Dye-Sensitized $\mathrm{TiO}_{2}$ is independent of light intensity [34]. In other words, the light intensity has no effect on the equilibrium constant $K$ but

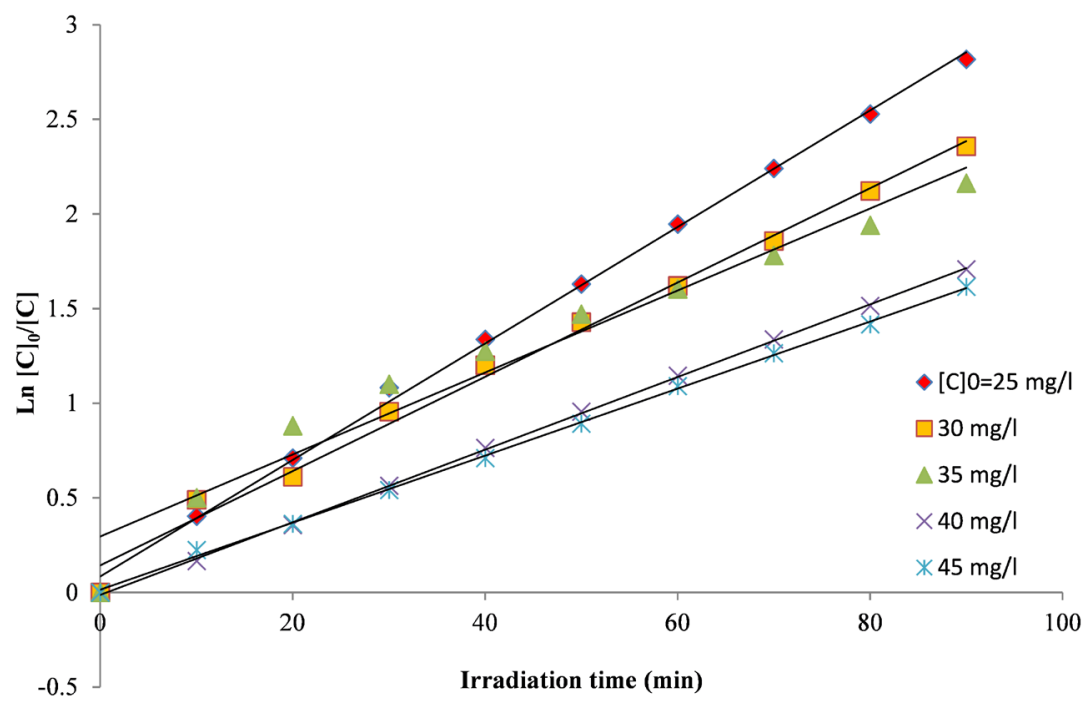

Fig. 3. The plots of $\ln \left([C]_{0} /[C]\right)$ versus irradiation time at different initial MB concentrations. 


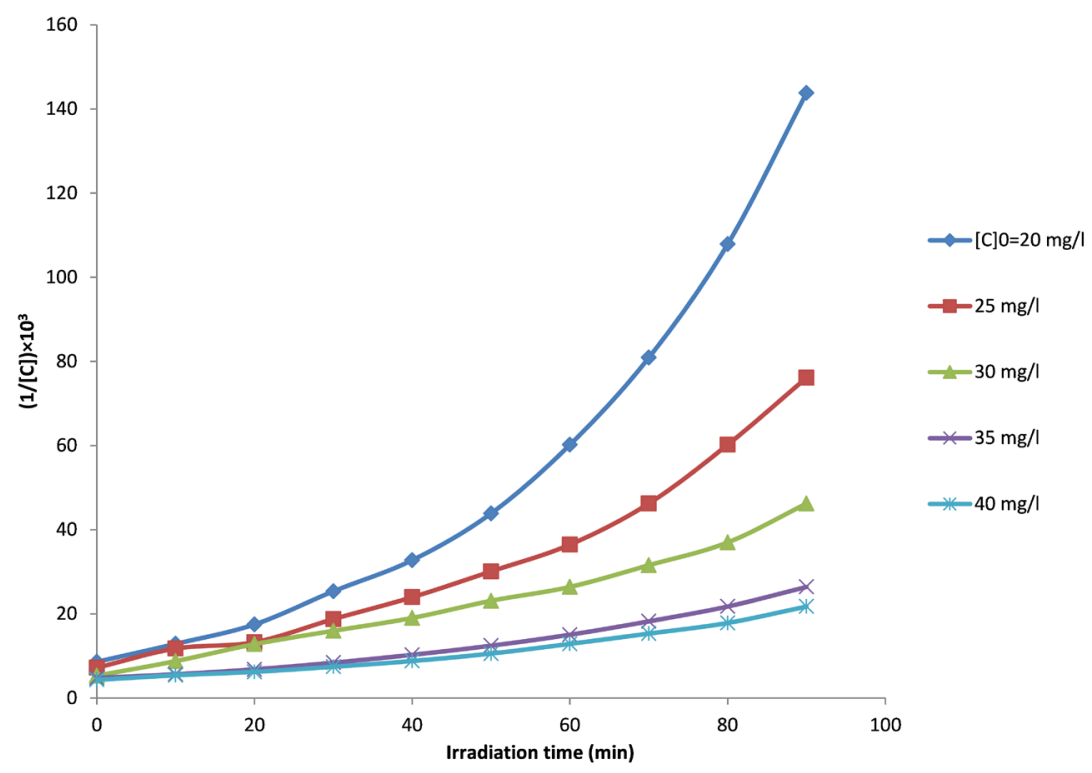

Fig. 4. The plots of $1 /[C]$ versus irradiation time at different initial MB concentrations.

Table 1. The values of the pseudo-first- and -second-order rate constants and the corresponding correlation coefficients for the photocatalytic degradation of $\mathrm{MB}^{\mathrm{a}}$

\begin{tabular}{cccccc}
\hline$[C]_{0}\left(\mathrm{mg} \mathrm{L}^{-1}\right)$ & $k_{\mathrm{obs} 1}\left(\mathrm{~min}^{-1}\right)$ & $R^{2}{ }_{1}$ & $k_{\mathrm{obs} 2} \times 10^{-3}\left(\mathrm{~L} \mathrm{mg}^{-1} \mathrm{~min}^{-1}\right)$ & $\mathrm{R}_{2}^{2}$ & $1 / k_{\mathrm{obs} 1}\left(\mathrm{~min}^{-1}\right)$ \\
\hline 20 & 0.027 & 0.997 & 1.402 & 0.892 & 37.0 \\
25 & 0.024 & 0.992 & 0.717 & 0.926 & 41.7 \\
30 & 0.022 & 0.957 & 0.434 & 0.969 & 45.4 \\
35 & 0.021 & 0.999 & 0.234 & 0.949 & 47.6 \\
40 & 0.019 & 0.999 & 0.186 & 0.951 & 52.63 \\
\hline
\end{tabular}

${ }^{\text {a }}$ Photacatalytic reaction is run under UV irradiation using $\mathrm{ZnO}$ nanoparticles $\left(300 \mathrm{mg} \mathrm{L}^{-1}\right)$.

affects $k_{\mathrm{c}}$. Using the slope and intercept of the plotted line in Fig. 5, we obtained the equilibrium constant as $0.128 \mathrm{~L} \mathrm{mg}^{-1}$.

\subsection{Theoretical results}

As we discussed in the introduction, the treatment of the L-H kinetic model is subjected to the assumptions that the RDS of photocatalytic reactions involves reactants present in a monolayer at the photocatalyst-solution interface [12]. In addition, the studied photocatalytic reaction of this work obeys the L-H kinetic model (the plot of $1 / k_{\text {obs } 1}$ versus $[C]_{0}$ is linear with correlation coefficient close to $1, R^{2}=0.9917$ ). Then, we studied the adsorption properties of $\mathrm{MB}$ on $\mathrm{ZnO}$ (0001) facet using DFT methods. First, the geometrical structure of MB is optimized (see Fig. 6. for the optimized structure of MB). Then the optimized structure of $\mathrm{MB}$ is located on the $\mathrm{ZnO}$ (0001) facet

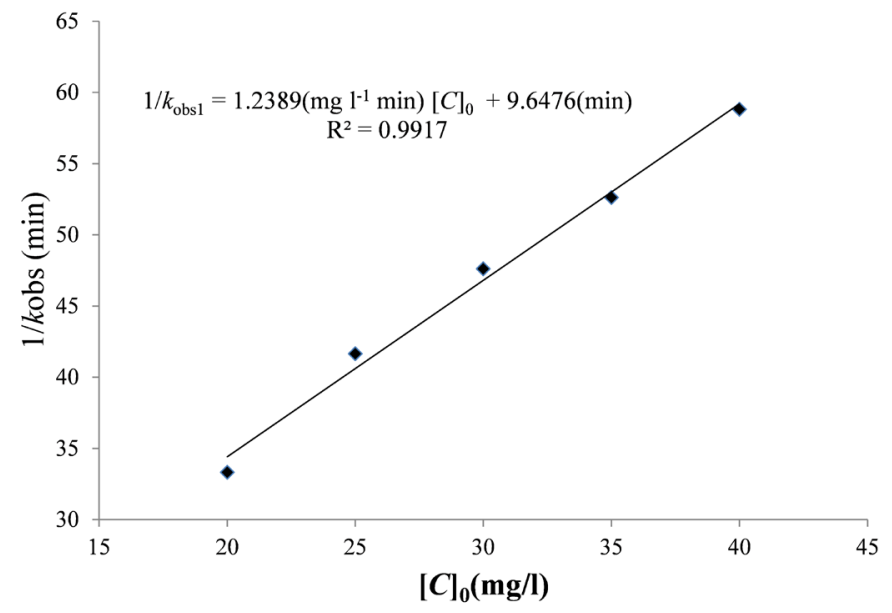

Fig. 5. The plot of $1 / k_{\text {obs } 1}$ versus $[\mathrm{C}]_{0}$. 


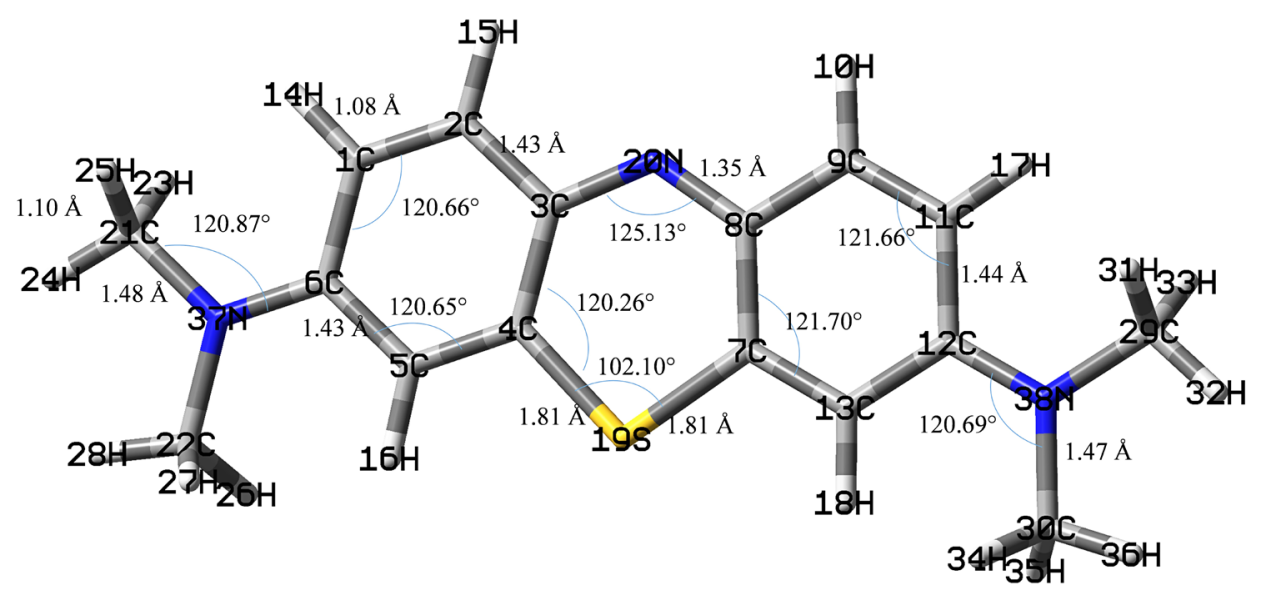

Fig. 6. The optimized structure of MB, representing the atom names, angles and bond lengths.

model (Fig. 2.). Finally, MB is optimized on the facet model. Fig. 7. shows the optimized structure of MB on (0001) facet of $\mathrm{ZnO}$. According to Fig. 7., the orientation of the aromatic rings of the adsorbed MB is almost parallel to the surface and two methyl hydrogens of $\mathrm{MB}(23 \mathrm{H}$ and $33 \mathrm{H}$; the atom naming is according to Fig. 6) are the closest atoms to the surface.

We calculated the adsorption energy of $\mathrm{MB}$ on $\mathrm{ZnO}(0001)$ facet, $E_{\text {ads }}$ as $-240.2 \mathrm{~kJ} \mathrm{~mol}^{-1}$. The calculated value of $E_{\text {ads }}$ is in the range of chemical adsorption energies $\left(-50\right.$ to $-400 \mathrm{~kJ} \mathrm{~mol}^{-}$ ${ }^{1}$ ). This energy means that $\mathrm{MB}$ is strongly adsorbed on the $\mathrm{ZnO}$ surface. This strong adsorption causes negative charge transfer from $\mathrm{MB}$ to $\mathrm{ZnO}$. Table 2 summarizes the calculated NBO charges of the MB atoms before and after the adsorption, and the charge changes of the $\mathrm{MB}$ atoms due to adsorption processes $(\Delta Q)$. The sum of the $\Delta Q$ values show that the adsorbed MB has lost a negative charge of -0.665 value to $\mathrm{ZnO}$. Gaining or losing charge by a molecule makes it energized and unstable. As we discussed in the introduction, the UV irradiation on a photocatalyst makes electron-hole pairs. The generated pairs generate free radicals (e.g. hydroxyl radicals) which undergo secondary reactions. A hydroxyl radical can react with an energized substrate faster than with a stable one. In other words, the adsorbed $\mathrm{MB}$ on $\mathrm{ZnO}$ surface undergoes a faster degradation than an unabsorbed MB. In summary, the adsorption of MB on the photocatalyst, which is the critical step in the L-H model and in the photocatalytic reaction of this work, makes MB energized and unstable. Then, the energized substrate undergoes a faster reaction with the free radicals and then undergoes a faster degradation. The computational results indicate that the adsorption of $\mathrm{MB}$ on $\mathrm{ZnO}$ is a critical step in the photocatalytic reaction.

\section{Conclusion}

The present work has focused on the adsorption and photodegradation of $\mathrm{MB}$ on $\mathrm{ZnO}$ nano-particles. The reaction was carried out in a Pyrex photoreactor, equipped with a Krypton lamp. To ensure the reaction order of $\mathrm{MB}$, both pseudo-first- and pseudo-second-order kinetics were tested. The pseudo-first-order equation is the model that gives the best fit to the experimental data. The obtained kinetics data were nicely fitted to the

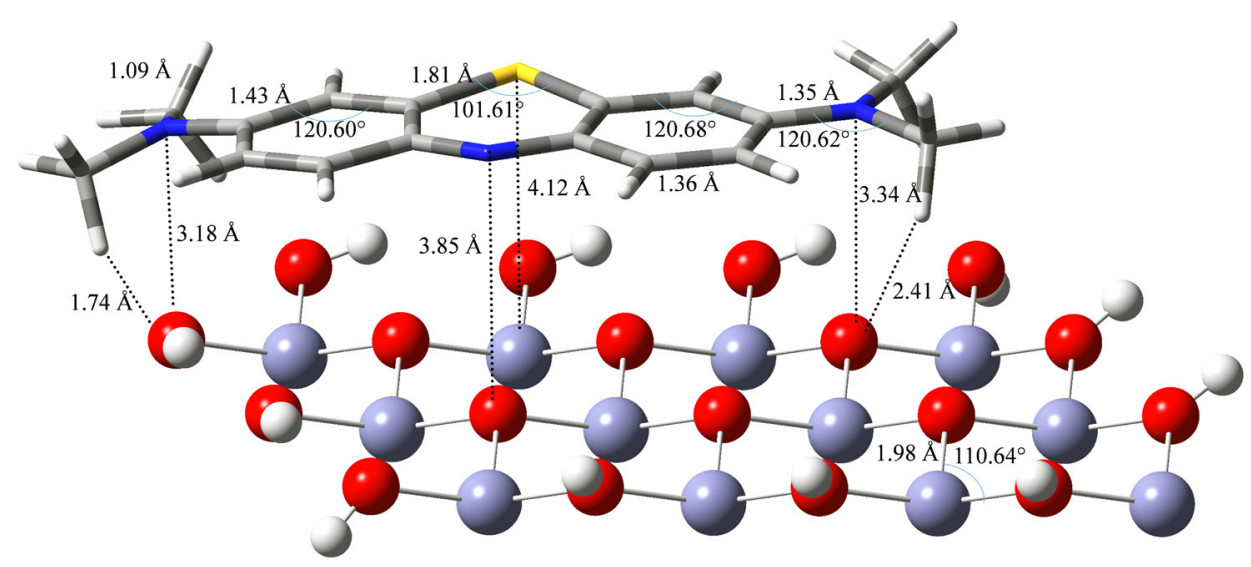

Fig. 7. The optimized structure of $\mathrm{MB}$ on the $\mathrm{Zn}_{12} \mathrm{O}_{18} \mathrm{H}_{12}$ cluster. 
Table 2. The calculated NBO charges on MB atoms before and after adsorption and the charge changes of atoms due to adsorption processes $(\Delta \mathrm{Q})$.

\begin{tabular}{|c|c|c|c|}
\hline & $\mathrm{MB}$ & MB-0001 & $\Delta \mathrm{Q}$ \\
\hline $1 \mathrm{C}$ & -0.276 & -0.237 & 0.039 \\
\hline $2 \mathrm{C}$ & -0.156 & -0.159 & -0.003 \\
\hline $3 \mathrm{C}$ & 0.114 & 0.189 & 0.075 \\
\hline $4 \mathrm{C}$ & -0.148 & -0.157 & -0.009 \\
\hline $5 \mathrm{C}$ & -0.304 & -0.267 & 0.037 \\
\hline $6 \mathrm{C}$ & 0.245 & 0.254 & 0.009 \\
\hline $7 \mathrm{C}$ & -0.148 & -0.163 & -0.015 \\
\hline $8 \mathrm{C}$ & 0.114 & 0.193 & 0.079 \\
\hline $9 \mathrm{C}$ & -0.156 & -0.157 & -0.001 \\
\hline $10 \mathrm{H}$ & 0.280 & 0.292 & 0.012 \\
\hline $11 \mathrm{C}$ & -0.276 & -0.229 & 0.047 \\
\hline $12 \mathrm{C}$ & 0.245 & 0.234 & -0.011 \\
\hline $13 \mathrm{C}$ & -0.304 & -0.233 & 0.071 \\
\hline $14 \mathrm{H}$ & 0.266 & 0.264 & -0.002 \\
\hline $15 \mathrm{H}$ & 0.280 & 0.284 & 0.004 \\
\hline $16 \mathrm{H}$ & 0.265 & 0.27 & 0.005 \\
\hline $17 \mathrm{H}$ & 0.266 & 0.273 & 0.007 \\
\hline $18 \mathrm{H}$ & 0.265 & 0.274 & 0.009 \\
\hline $19 \mathrm{~S}$ & 0.441 & 0.494 & 0.053 \\
\hline $20 \mathrm{~N}$ & -0.338 & -0.354 & -0.016 \\
\hline $21 \mathrm{C}$ & -0.508 & -0.512 & -0.004 \\
\hline $22 \mathrm{C}$ & -0.509 & -0.512 & -0.003 \\
\hline $23 \mathrm{H}$ & 0.253 & 0.249 & -0.004 \\
\hline $24 \mathrm{H}$ & 0.262 & 0.27 & 0.008 \\
\hline $25 \mathrm{H}$ & 0.253 & 0.253 & 0.000 \\
\hline $26 \mathrm{H}$ & 0.252 & 0.296 & 0.044 \\
\hline $27 \mathrm{H}$ & 0.252 & 0.245 & -0.007 \\
\hline $28 \mathrm{H}$ & 0.263 & 0.246 & -0.017 \\
\hline $29 \mathrm{C}$ & -0.508 & -0.524 & -0.016 \\
\hline $30 \mathrm{C}$ & -0.509 & -0.527 & -0.018 \\
\hline $31 \mathrm{H}$ & 0.253 & 0.254 & 0.001 \\
\hline $32 \mathrm{H}$ & 0.262 & 0.328 & 0.066 \\
\hline $33 \mathrm{H}$ & 0.253 & 0.249 & -0.004 \\
\hline $34 \mathrm{H}$ & 0.252 & 0.247 & -0.005 \\
\hline $35 \mathrm{H}$ & 0.252 & 0.322 & 0.070 \\
\hline $36 \mathrm{H}$ & 0.263 & 0.256 & -0.007 \\
\hline $37 \mathrm{~N}$ & -0.355 & -0.304 & 0.051 \\
\hline $38 \mathrm{~N}$ & -0.355 & -0.235 & 0.120 \\
\hline Sum & 1.001 & 1.665 & 0.665 \\
\hline
\end{tabular}

$\mathrm{L}-\mathrm{H}$ kinetic model. The value of the adsorption equilibrium constant is calculated as $0.128 \mathrm{~L} \mathrm{mg}^{-1}$.

To understand the adsorption properties, the $\mathrm{ZnO}$ (0001) facet is modeled, using the quantum cluster approach. The DFT results show that the orientation of the aromatic rings of $\mathrm{MB}$ on the facet is almost parallel. Our calculations show a strong adsorption of $\mathrm{MB}$ and a negative charge transferring from $\mathrm{MB}$ to $\mathrm{ZnO}$. Losing the negative charge makes $\mathrm{MB}$ energized. As a result, the photogenerated hydroxyl radicals can react with the energized substrate faster. In conclusion, the adsorbed $\mathrm{MB}$ on $\mathrm{ZnO}$ surface undergoes a faster degradation than an unabsorbed MB. Our calculations indicate that the adsorption of MB is a critical step in the photocatalytic reaction. The adsorption causes a partial negative charge transfer from the substrate to the photocatalyst and makes the substrates more energized. The energized substrates undergo faster photodegradation by the hydroxyl radicals. In fact, the photocatalytically produced hydroxyl radicals attack to the activated $\mathrm{MB}$ on the surface of $\mathrm{ZnO}$.

\section{References}

1. Xu, C.; Rangaiah, G.P., Zhao, X.S., Ind. Eng. Chem. Res., 2014, 53, 14641-14649.

2. Che Ramli, Z.A.; Asim, N.; Isahak, W.N.R.W.; Emdadi, Z.; Ahmad-Ludin, N.; Yarmo, M.A., Sopian, K., Sci. World J., 2014, 2014, 8.

3. Liu, B.; Zhao, X.; Terashima, C.; Fujishima, A., Nakata, K., Phys. Chem. Chem. Phys., 2014, 16, 8751-8760.

4. Fan, H.; Zhao, X.; Yang, J.; Shan, X.; Yang, L.; Zhang, Y.; Li, X., Gao, M., Catal. Commun., 2012, 29, 29-34.

5. Senthilraja, A.; Subash, B.; Dhatshanamurthi, P.; Swaminathan, M., Shanthi, M., Spectrochim. Acta, Part A, 2015, 138, 31-37.

6. Daneshvar, N.; Rasoulifard, M.; Khataee, A., Hosseinzadeh, F., J. Hazard. Mater, 2007, 143, 95-101.

7. Boppella, R.; Anjaneyulu, K.; Basak, P., Manorama, S.V., J. Phys. Chem. C, 2013, 117, 4597-4605.

8. Xiao, Y.; Lu, L.; Zhang, A.; Zhang, Y.; Sun, L.; Huo, L., Li, F., ACS Appl. Mater. Interfaces, 2012, 4, 3797-3804.

9. Alenezi, M.R.; Alshammari, A.S.; Jayawardena, K.D.G.I.; Beliatis, M.J.; Henley, S.J., Silva, S.R.P., J. Phys. Chem. C, 2013, 117, 17850-17858.

10. Khodja, A.A.; Sehili, T.; Pilichowski, J.-F., Boule, P., Journal of Photochemistry and Photobiology A: Chemistry, 2001, 141, 231-239.

11. Kohtani, S.; Kamoi, Y.; Yoshioka, E., Miyabe, H., Catalysis Science \& Technology, 2014, 4, 1084-1091.

12. Chakrabarti, S., Dutta, B.K., J. Hazard. Mater, 2004, 112, 269-278.

13. Konstantinou, I.K.; Sakellarides, T.M.; Sakkas, V.A., Albanis, T.A., Environ. Sci. Technol., 2001, 35, 398-405.

14. Saien, J., Khezrianjoo, S., J. Hazard. Mater, 2008, 157, 269-276.

15. Guzsvány, V.J.; Csanádi, J.J.; Lazić, S.D., Gaál, F.F., J. Braz. Chem. Soc., 2009, 20, 152-159.

16. Oh, W.-C.; Zhang, F.-J., Chen, M.-L., J. Ind. Eng. Chem., 2010, 16, 299-304.

17. Wahab, H., Koutselos, A., J. Mol. Model., 2009, 15, 1237-1244.

18. Trubitsyn, D.A., Vorontsov, A.V., Comput. Theor. Chem., 2013, 1020, 63-71.

19. Izadyar, M.; Balgerdi, R., Pourayoubi, M., Prog. React. Kinet. Mech., 2015, 40, 128-142. 
20. Magham, A.; Morsali, A.; Es' haghi, Z.; Beyramabadi, S., Chegini, H., Prog. React. Kinet. Mech., 2015, 40, 119-127.

21. Lee, C., Aikens, C.M., Comput. Theor. Chem., 2013, 1013, 32-45.

22. Gurkan, Y.Y.; Kasapbasi, E., Cinar, Z., Chem. Eng. J., 2013, 214, 34-44.

23. Yang, L.; Taylor, R.; de Jong, W.A., Hase, W.L., J. Phys. Chem. C, 2011, 115, 12403-12413.

24. Sun, C.; Dong, L.; Yu, W.; Liu, L.; Li, H.; Gao, F.; Dong, L., Chen, Y., Journal of Molecular Catalysis A: Chemical, 2011, 346, 29-38.

25. Onal, I.; Soyer, S., Senkan, S., Surface Science, 2006, 600, $2457-$ 2469.

26. Huang, M.; Weng, S.; Wang, B.; Hu, J.; Fu, X., Liu, P., J. Phys. Chem. C, 2014, 118, 25434-25440.

27. Becke, A.D., J. Chem. Phys., 1993, 98, 5648-5652.

28. Lee, C.; Yang, W., Parr, R.G., Phys. Rev. B, 1988, 37, 785-789.

29. Frisch, M.J.; Trucks, G.W.; Schlegel, H.B.; Scuseria, G.E.; Robb, M.A.; Cheeseman, J.R.; Montgomery, J.A.; Vreven, T.; Kudin, K.N.; Burant, J.C.; Millam, J.M.; Iyengar, S.S.; Tomasi, J.; Barone, V.; Mennucci, B.; Cossi, M.; Scalmani, G.; Rega, N.; Petersson, G.A.; Nakatsuji, H.; Hada, M.; Ehara, M.; Toyota, K.; Fukuda,
R.; Hasegawa, J.; Ishida, M.; Nakajima, T.; Honda, Y.; Kitao, O.; Nakai, H.; Klene, M.; Li, X.; Knox, J.E.; Hratchian, H.P.; Cross, J.B.; Bakken, V.; Adamo, C.; Jaramillo, J.; Gomperts, R.; Stratmann, R.E.; Yazyev, O.; Austin, A.J.; Cammi, R.; Pomelli, C.; Ochterski, J.W.; Ayala, P.Y.; Morokuma, K.; Voth, G.A.; Salvador, P.; Dannenberg, J.J.; Zakrzewski, V.G.; Dapprich, S.; Daniels, A.D.; Strain, M.C.; Farkas, O.; Malick, D.K.; Rabuck, A.D.; Raghavachari, K.; Foresman, J.B.; Ortiz, J.V.; Cui, Q.; Baboul, A.G.; Clifford, S.; Cioslowski, J.; Stefanov, B.B.; Liu, G.; Liashenko, A.; Piskorz, P.; Komaromi, I.; Martin, R.L.; Fox, D.J.; Keith, T.; Laham, A.; Peng, C.Y.; Nanayakkara, A.; Challacombe, M.; Gill, P.M.W.; Johnson, B.; Chen, W.; Wong, M.W.; Gonzalez, C., Pople, J.A., in, 2003.

30. Hay, P.J., Wadt, W.R., J. Chem. Phys., 1985, 82, 270-283.

31. Reed, A.E.; Curtiss, L.A., Weinhold, F., Chem. Rev., 1988, 88, 899-926.

32. Reed, A.E., Weinhold, F., J. Chem. Phys., 1983, 78, 4066-4073.

33. Turchi, C.S., Ollis, D.F., J. Catal., 1990, 122, 178-192.

34. Chowdhury, P.; Moreira, J.; Gomaa, H., Ray, A.K., Ind. Eng. Chem. Res., 2012, 51, 4523-4532. 